\title{
真空蒸発法によるコバルト磁性流体の作製に関する研究
}

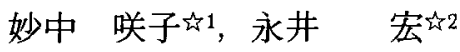 \\ 真島 一彦虹, 勝山茂虹
}

的大阪大学大学院工学研究科, 宁565 吹田市山田丘2-1.

如2 大阪大学工学部， $\mathbf{T} 565$ 吹田市山田丘2-1.

\section{Studies of Preparation of Co Magnetic Fluid by Vacuum Evaporation Method.}

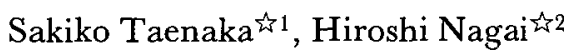

Kazuhiko Majima ${ }^{\star 2}$ and Shigeru Katsuyama ${ }^{\star 2}$

↔1 Graduate School of Osaka University, 2-1 Yamadaoka, Suita 565.

मै2 Department of Materials Science and Engineering, Osaka University, 2-1 Yamadaoka, Suita 565.

Received December 9, 1991

Cobalt magnetic fluid was prepared by vacuum evaporation method. The colloidal fluid obtained was heated up to $150,200,250$ and $280^{\circ} \mathrm{C}$ for $20 \mathrm{~min}$ in Ar atmosphere. The effects of concentration of surfactant and heat treatment temperature on particle size and its distribution were studied by torsion magnetometer and TEM. As a result, the particle size was controlled by varying the relative concentration of the particles to surfactant and heat treatment temperature. It was difficult to redisperse the cobalt particles flocculation. so it is suggested to use the oil substrate with the high concentration of surfactant. The saturation magnetization of the fluid was improved by heat treatment.

\section{I 楮言}

磁性流体は，强磁性金属微粒子を界面活性剂 を介し溶媒中に分散させたものである．現在使 用されている磁性流体は，微粒子としてフェラ イト $\left(\mathrm{MFe}^{2} \mathrm{O}_{4}, \mathrm{M}=\mathrm{Fe}, \mathrm{Mn}, \mathrm{Zn}\right.$ 等) を用いた酸化物 磁性流体で，微粒子自身の飽和磁化が小さいた めに磁性流体としての飽和磁化も200〜500 Gが 限度である 金属 ( $\mathrm{Fe}, \mathrm{Co}, \mathrm{Ni}$. 及びこれらの合金)を微粒子 として用いると最高1500G程度の磁性流体が得 られると予想されているが2，高い磁化を有す るために磁気的吸引力により合体し，凝集しゃ
すいこと，また製造プロセスで粒子が酸化しゃ すいことなど安定な分散を得ることが難しく， 化学的, 物理的にいろいろな方法が試みられて いるがる々，未だ十分な成果を上げるに至ってい ない。

本研究では，真空蒸発法によりコバルト磁性 流体を作製し，熱処理温度と界面活性剂濃度が 粒径及び熱処理性に与える影響を調查しより 高い蚫和磁化を持つ金属磁性流体を得る方法に ついて検討した. 


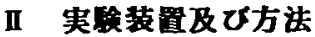

\section{1 䒾置}

本実满に用いた真空蒸着装置の概略をPig. 1 に示す. 蒸発源には，タングステン線抵抗加熱 アルミナるつばを用いた。下地液は，ドラム底 部に保持されており，ドラムの回転 $(2 \mathrm{rpm}) に$ 伴い液体膜となって内壁に展開する，蒸発した コバルトは，この液体膜表面に付着して徽粒子 を形成しドラム底部に回収され，次第に高濃度 に粒子が分散したコロイド溶被が得られる。

得られた磁性流体をミッロフラスコに入れ,

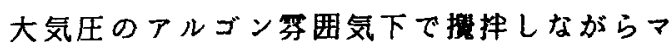
ントルヒーターで $150,200,250,280^{\circ} \mathrm{C} の$ 各温度 で20分間加熱を行った。

\section{2 . 2 実験方法}

蒸発原料として純度99\%のコバルト粉末を圧 粉後アーク溶解しボタン状の試料とした。下地 液としては，アルキルナフタレンと，予め不純 物除去のために真空中で $150^{\circ} \mathrm{C} 30$ 分加熱処理し た界面活性拜（ポリブテニルコハク酸イミドテ トラエチレンペンタミン）を10,30wt\%㮇加し混 合したものを用意した。得られた蒸着試料に対 し熱処理をほどこし磁気測定とTEM䚁察を行っ た。 さらに一部の試料については, 熱処理の際 得られたゲル相の約 $10 \mathrm{wt}$ \%に相当する界面活性 剤を新たに添加し， $150^{\circ} \mathrm{C}$ で20分間熱処理を行 った.

\section{III 耤果及び考察}

Fig. 2に界面活性剤を10wt％添加し，真空蒸着

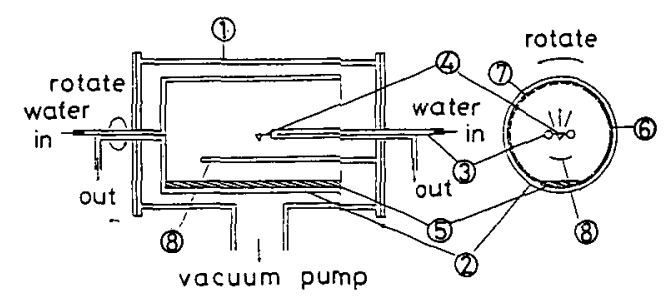
(1) Work Chamber
(2) Drum
(3) Water Cooled Electrode (4)Crusible
(5) 0 il with Co Particles (6) 0 il Substrate
(7) Co Particles
(8)Stainless Board

Fig. 1 Schematic diagram of the apparatus for the vacuum evaporation.
して得られた試料（O）とそれを $150^{\circ} \mathrm{C} て ゙$ 熱処 理して得られた試料の磁化曲線を示す. 熱処理 を施すといずれの温度でもソル相（[）とゲル 相（口）の二相に分噰した。磁化曲線からもわ かるようにンル相はほとんど磁性を示さず，粒 子は全てゲル相に移野している。

Fig.3に界面活性郕を30wt添加し作製した試 料の磁化曲線を示す．熱処理にかけると10 w t\% の場合と同㴍二相分雕したが，30nt\%ではソル 相（口）の蚫和磁化の方がゲル相（四）のもの より高くなる傾向があった。この傾向が $250^{\circ} \mathrm{C}$ まで続き，280 Cでは逆にゲル相の盷和磁化が 高くなった。これは，界面活性剂が熱処理によ って変成を受けたためと思われる4!。

熱処理前後における粒径の変化をTEMにより 観察した。30wt\%で蒸着したままの試料とそれ を各温度で熱処理後、ソル状態になったものの TEM写真をPhoto.1に示す. どの温度で得られた 粒子す晶群のない球状の粒子で, 一樣に分布し ていた。 また，熱処理温度の上昇に伴い粒径の 增加が観察された。

TEM写真加ら計算した平均粒径を熱処理温度 に対してプロットしたものをFig.4に示す．界 面活性剂濃度10,30wt\%ともに温度の上昇に伴い

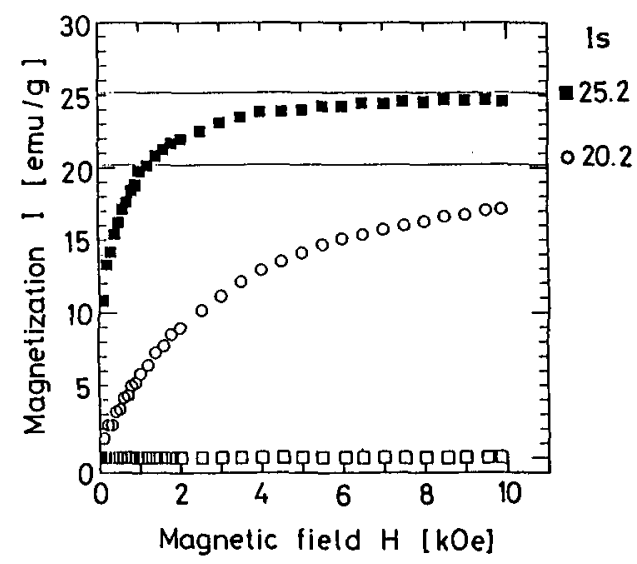

Fig. 2 Magnetization curve of Co magnetic fluid (10wt\% surfactant).

Co particle concentration: $0.24 \mathrm{~g} / \mathrm{cc}$

$O$ as evaporated

- after heat treatment at $150^{\circ} \mathrm{C} 20 \mathrm{~min}$ (gel)

after heat treatment at $150^{\circ} \mathrm{C} 20 \mathrm{~min}$ (sol) 


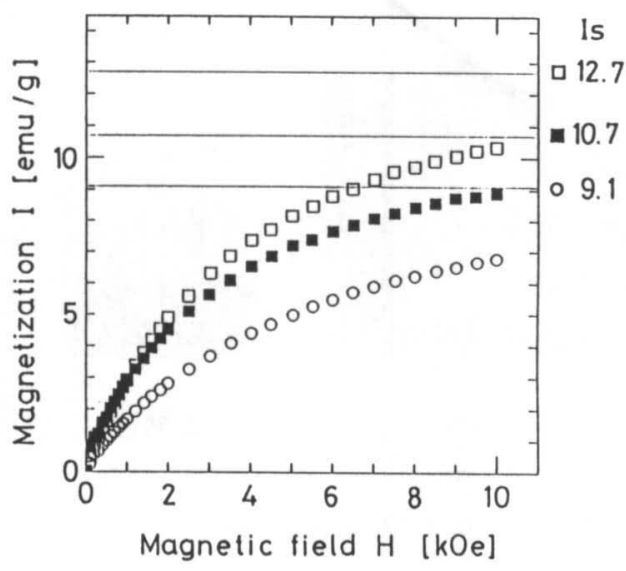

Fig. 3 Magnetization curve of Co magnetic fluid ( 30 wt\% surfactant).

Co particle concentration; $0.14 \mathrm{~g} / \mathrm{cc}$

as evaporated

a after heat treatment at $200^{\circ} \mathrm{C} 20 \mathrm{~min}$ (gel)

af ter heat treatment at $200^{\circ} \mathrm{C} 20 \mathrm{~min}$

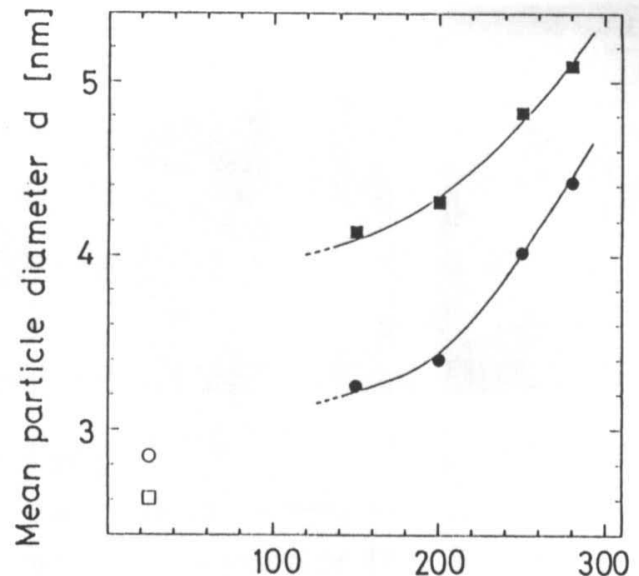

Heat treatment temperature $\left[{ }^{\circ} \mathrm{C}\right]$

Fig. 4 Effect of heat treatment temperature and concentration of surfactant on mean particle diameter.

as evaporated (10wt\% surfactant)

$\square$ as evaporated ( 30 wt \% surfactant)

- after heat treatment( $10 w t \%$ surfactant)

after heat treatment ( 30 wt\% surfactant)
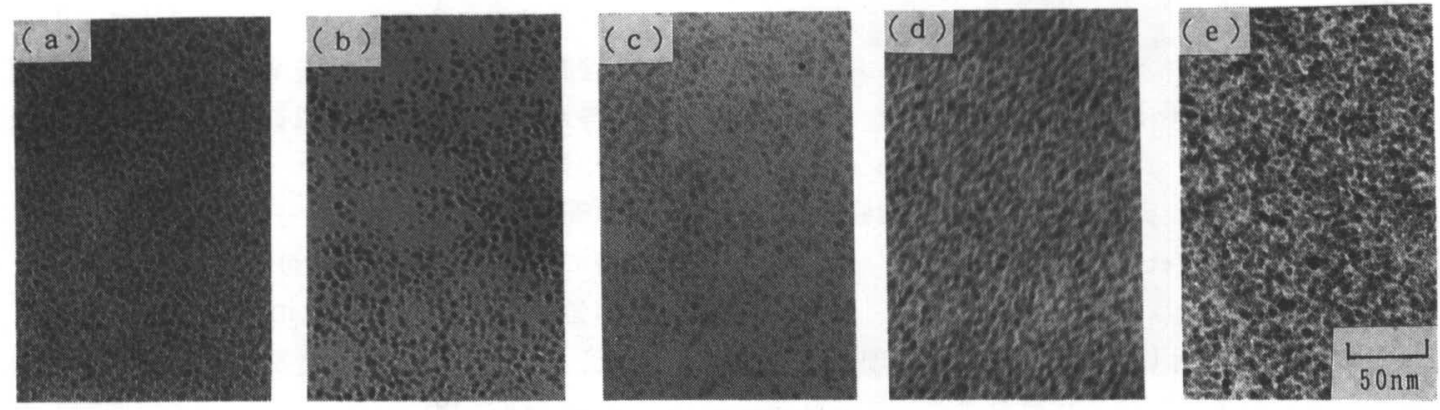

Photo. 1 TEM photographs:Effect of heat treatment temperature on particle size of Co ultrafine particles ( $30 w t \%$ surfactant). Co particle concentration; $0.14 \mathrm{~g} / \mathrm{cc}$ (a) as evaporated (b) $150^{\circ} \mathrm{C}$ (c) $200^{\circ} \mathrm{C}$ (d) $250^{\circ} \mathrm{C}$ (e) $280^{\circ} \mathrm{C}$

粒径が增大する. 一方, 蒸着したままの試料で は10wt\%の方が粒径が大きいのに対し，熱処理 を施すと $30 \mathrm{w}$ t\%の方が大きくなるという逆転現 象を示した.

その原因を考えるために, 界面活性剤濃度10 w $t$ \%で粒子濃度を変化させTEMにより観察した （Photo. 2）。粒子濃度が低いとき，30wt\%の場 合 (Photo. 1) と同様, 均一な分布をしている (Photo.2(a)) . 濃度が上昇するに従って室温 であ粒径の增大は起こるが分散状態を保ってい る(Photo. 2(b)). 更に濃度が上がると次第に
粒子分布に粗密ができ始め (Photo. 2(c)), つい には島状の凝集物を形成するに至る(Photo.2 (d)）. 蒸着したままの粒子が10w t\%の方が大き いのは，粒成長後のものをカゥントしたためと 考えられる．また先に述べたように，界面活性 剂濃度 $10 \mathrm{wt} \%$ の場合熱処理によって粒子が全て 沈降したのは，この疑集物形成によるむのと考 えられる。

次に, 熱処理後得られたゲル相のTEM写真を Photo.3に示す.（b）に見られるように界面活性 剤湌度 $30 \mathrm{wt}$ \%の場合, ゲル相でも一様な分布を 


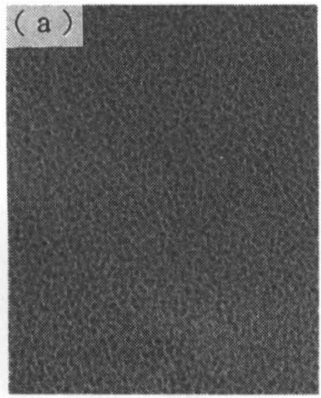

$0.08 \mathrm{~g} / \mathrm{cc}$

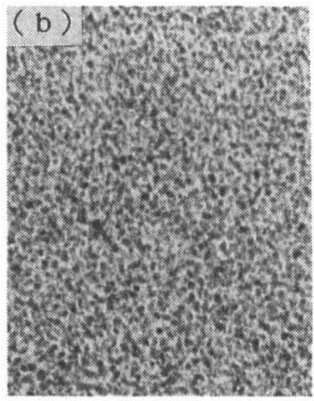

$0.17 \mathrm{~g} / \mathrm{cc}$

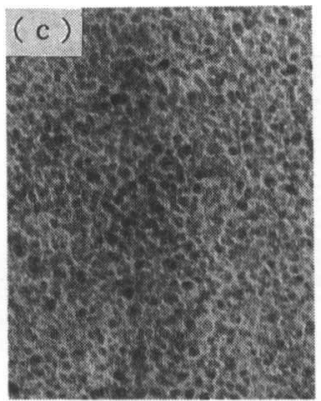

$0.22 \mathrm{~g} / \mathrm{cc}$

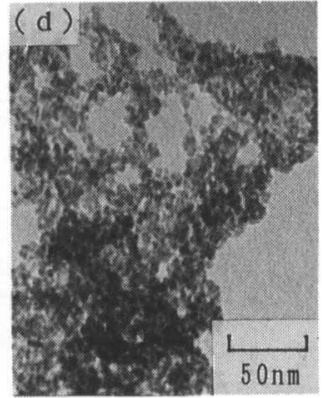

$0.30 \mathrm{~g} / \mathrm{cc}$

Low Relative concentration of Co particle

High

Photo. 2 TEM photographs as evaporated: Effect of Co particle concentration on particle distribution ( 10 wt\% surfactant).
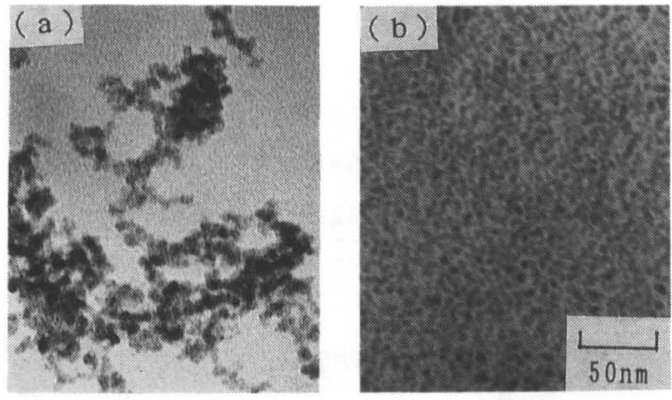

Photo. 3 TEM photographs: Effect of heat treatment $\left(250^{\circ} \mathrm{C} 20 \mathrm{~min}\right)$ on particle distribution in gel phase. (a) 10 wt $\%, 0.29 \mathrm{~g} / \mathrm{cc}$, (b) $30 \mathrm{wt} \%, 0.15 \mathrm{~g} / \mathrm{cc}$

示しているのに対し，10w t\%では熱処理前の島 状の凝集物のままで分散状態の改善は見られな かった. 30wt\%の場合ゾル相 (Photo.1) とゲル 相 (Photo. 3(b)) の分散状態に差がないのに二 相分離するのは磁化曲線 (Fi g. 3) 加ら判断す ると, より金属的な粒子は界面活性剤との相性 がよく下地液中に分散できるが, 酸化物的な粒 子は分散できず沈降したすのと考えられる.

10wt\%の場合, Photo. 3(a)に見られるように 二相分離するのは界面活性剂の不足が原因と考 えられるので,この二相分離によって磁性流体 の濃縮を試みた。 まず比表面積を減らし界面活 性剂の余裕をつくるために $150^{\circ} \mathrm{C} 20$ 分間の熱処 理によってできたゾル相を除去した後，ゲル相 の約 $10 \mathrm{wt}$ \% に相当する界面活性剂を新たに添加 し, 再度 $150^{\circ} \mathrm{C} 20$ 分間の熱処理によって再分散
を試みた。 その結果, 再分散処理後む, 試料は 二相分離を起こした。できたゾ相は若干の磁 性を示しており,ゲル相からゾル相への粒子の 移動が見られたが，依然として島状分布のまま で分散状態の改善はできなっかった。

\section{IV 䊅㻅}

真空蒸発法により作製した磁性流体に対し， 熱処理温度と界面活性剂濃度が粒径及び熱処理 性に与える影響について調查を行った結果, 以 下の知見を得た。

(1)界面活性剤に対する粒子の相対濃度と熱処 理により粒径の制御が可能である.

（2）熱処理により磁性流体の飽和磁化が増大し た。例えば，界面活性剤濃度 $30 \mathrm{w}$ \%の場合 7. $6[\mathrm{emu} / \mathrm{g}]$ から17.0[emu/g]まで増加した (94. 9[G]から227[G]に相当する).

(3)一度粒子の疑集を起こすと再分散は非常に 困難である. 分散安定な試料を得るには， 真空蒸着時に界面活性剂濃度の高い下地液 を用いる方が良いと考えられる。

\section{文献}

1) 磁性流体入門: 神山 新一, 産業図書, (1989) pp. 9.

2) P. C. Schol ten:J. Mag. Mag. Mat., 39 (1989) 99.

3）磁性流体一基礎と応用:武富 荒, 近角聡信 日刊工業新聞社, (1988)pp. 109.

4) 中谷功, 高橋務, 古林 孝夫, 花岡 博明: 金属材料技術研究所研究報告集, 9(1988) 155 . 